\title{
Transferable or mobilisable antibiotic resistance in Shigella dysenteriae types 1,2,3,4,6 and 7 isolated in Ethiopia during 1974-85
}

\author{
A. GEBRE-YOHANNES and B. S. DRASAR*
}

\section{National Research Institute of Health, Box 1242, Addis Ababa, Ethiopia and "London School of Hygiene and Tropical Medicine, London WCTE 7HT}

\begin{abstract}
Summary. A total of 199 Shigella dysenteriae isolates resistant to one or more antibiotics and belonging to types 1, 2, 3, 4, 6 and 7 was examined by one-step broth mating with Escherichia coli K12 and, if non-conjugative, additionally by triparental crosses with the conjugative plasmids $\mathrm{X}$ and $\Delta$. Of the $S$. dysenteriae type 1 (Shiga's bacillus) strains, $96 \%$ harboured conjugative plasmids. During 1974-79, isolates of Shiga's bacillus carried conjugative plasmids coding for ACSSuT (ampicillin, chloramphenicol, streptomycin, sulphonamide, tetracycline) resistance that transferred at low frequencies $\left(<10^{-4}\right)$. After 1980 , however, about $50 \%$ of isolates of Shiga's bacillus with this resistance $(R)$-type carried conjugative plasmids that transferred at high frequencies $\left(10^{\circ}-10^{-2}\right)$ and that expressed the ACT determinant only. The introduction of a new clone of Shiga's bacillus into Ethiopia in 1980 is suspected. Conjugative plasmids coding for SSuT resistance were detected in $S$. dysenteriae types 2,3 , and 4 . Non-conjugative SSu determinants in $S$. dysenteriae type 3 were mobilised by conjugative plasmids $\mathrm{X}$ and $\Delta$. R-type CSSuT in strains of types 2 and 7, and R-type ACST in type-3 strains were neither transferable nor mobilisable and are probably determined chromosomally.
\end{abstract}

\section{Introduction}

The phenomenon of R-plasmid mediated multiple antibiotic resistance was first noted in Japan during the 1950s in bacterial strains that were resistant simultaneously to chloramphenicol, streptomycin, sulphonamides and tetracycline (Suzuki et al., 1956). Akiba et al. (1960) proposed the theory that the factor governing such multiresistance could be transmitted by cellular contact. At about the same time, Ochiai et al. (1959) transmitted resistance in vitro among strains of the genus Shigella and Escherichia coli.

Within the genus Shigella, R-plasmid mediated antibiotic multiresistance has been especially common in $S$. dysenteriae type 1 (Shiga's bacillus). The most dramatic incident so far reported has been the Central American epidemic in 1969-1971 (Mata et $a l ., 1970$ ). The outbreak in Mexico City (Olarte et al., 1976), and the recent Central African epidemic (Frost et al., 1981) are other examples.

In Ethiopia, the prevalence of various Shigella

Received 4 March 1988; accepted 19 May 1988. serotypes has been studied (Gebre-Yohannes and Habte-Gabr, 1984a), and their resistance patterns determined (Gedebou and Tassew, 1982; GebreYohannes and Habter-Gabr, 1984b). However, reports on R-plasmids are few (Gedebou and Tassew, 1979). The present study was undertaken to determine the prevalence of $\mathrm{R}$-plasmids in specific serotypes of $S$. dysenteriae, by use of standardised methods which included determination of transfer frequency and mobilisation of nonconjugative plasmids.

\section{Materials and methods}

\section{Shigella strains}

$S$. dysenteriae strains isolated from cases of endemic shigellosis and referred to the National Research Institute of Health, Addis Ababa were used. These strains were collected between 1974 and 1985 and were stored at $-70^{\circ} \mathrm{C}$ in trypticase soy yeast broth with glycerol $25 \% \mathrm{v} / \mathrm{v}$.

Serotype identification. Serotypes were identified by slide agglutination with commercial serotype-specific antisera (Difco). 


\section{Antibiotic susceptibility}

Sensitivity tests for each isolate were performed by the method of Bauer et al. (1966). E. coli (ATCC 25922) was used to control medium and sensitivity disks. The agents tested were: ampicillin (A), chloramphenicol (C), cephalothin $(\mathrm{Ce})$, kanamycin $(\mathrm{K})$, gentamicin $(\mathrm{G})$, polymyxin B $(\mathrm{Px})$, streptomycin $(\mathrm{S})$, sulphadiazine $(\mathrm{Su})$, tetracycline (T) and trimethoprim (Tp).

A total of 199 strains resistant to one or more drugs was selected for the genetic transfer studies.

\section{Genetic transfer studies}

Direct transfer of plasmids was examined by the methods of Anderson and Threlfall (1974). Broth cultures of donor Shigella strains and the recipient strain (E. coli $\mathrm{K} 12, \mathrm{~F}^{-}, \mathrm{Lac}^{+}$, $\mathrm{Nal}^{\mathrm{r}}$, prototrophic) were grown to exponential phase with continuous agitation at $37^{\circ} \mathrm{C}$. Equal volumes $(0.5 \mathrm{ml})$ of the cultures were mixed and incubated overnight at 28 and $37^{\circ} \mathrm{C}$. After incubation, serial tenfold dilutions were prepared in phosphate buffer and $0.01-\mathrm{ml}$ volumes were spread with a calibrated loop on MacConkey agar containing antimicrobial agents. Appropriate dilutions were spread on MacConkey agar without antibiotics to obtain colony counts of each parent. The plates of selective media were incubated overnight at $37^{\circ} \mathrm{C}$, and exconjugant colonies were counted. From each selective plate, 5-10 colonies were resistance typed by the agar dilution method with Steer's replicating apparatus (Steers et al., 1959). Transfer frequency was expressed as the proportion of resistant progeny per recipient cell.

Non-conjugative plasmids were mobilised by triparental crosses (Anderson and Threlfall, 1974) with the $\mathrm{Fi}^{+}$, group $\mathrm{F}_{\mathrm{II}}$ plasmid $\mathrm{X}$ and the $\mathrm{F}^{-}$, group $\mathrm{I}_{1}$ plasmid $\Delta$ (Enteric Reference Laboratory nos. 48R626 and RT641, respectively). The procedure was similar to that used to detect direct transfer except that $0.5 \mathrm{ml}$ of donor and $0.5 \mathrm{ml}$ of intermediate host (containing $\mathrm{X}$ or $\Delta$ ) were incubated for $18 \mathrm{~h}$ at $37^{\circ} \mathrm{C}$ before the addition of $1 \mathrm{ml}$ of the final recipient (E. coli $\mathrm{K} 12$ ).

\section{Results}

Table I shows the spectrum of R-types encountered, the number with conjugative plasmids, the R-phenotype transferred to $E$. coli $\mathrm{K} 12$ and the estimated transfer frequencies (for $S$. dysenteriae type I). Of $S$. dysenteriae type-1 isolates, $96 \%$ harboured conjugative plasmids, and most of these transferred at high frequencies.

Table II shows comparative transfer frequencies of conjugative plasmids in $S$. dysenteriae type 1 with R-type ACSSuT isolated during the years 1974-79 and 1980-85. Conjugative plasmids coding

Table I. Transferable antibiotic resistance in 132 strains of $S$. dysenteriae type 1 isolated in Addis Ababa, Ethiopia (1974-1985)

\begin{tabular}{|c|c|c|c|c|c|c|}
\hline \multirow{2}{*}{$\begin{array}{l}\text { Donor } \\
\text { R-type* }\end{array}$} & \multirow{2}{*}{$\begin{array}{l}\text { Number } \\
\text { tested }\end{array}$} & \multirow{2}{*}{$\begin{array}{l}\text { Number } \\
\text { with } \\
\text { R-plasmid }\end{array}$} & \multirow{2}{*}{$\begin{array}{c}\text { Recipient } \\
\text { R-type } \dagger\end{array}$} & \multicolumn{3}{|c|}{ Transfer frequency } \\
\hline & & & & High & Medium & Low \\
\hline Su & 1 & 1 & $\mathrm{Su}$ & + & & \multirow{13}{*}{$\begin{array}{l}+ \\
+\end{array}$} \\
\hline ACT & 5 & 5 & ACT & + & & \\
\hline $\mathrm{CSSu}$ & 1 & 1 & CSSu & + & & \\
\hline SSuT & 3 & 3 & $T$ & & + & \\
\hline CSSuT & 9 & 8 & CSSuT & + & & \\
\hline ACSSuT & 112 & 107 & $\mathrm{ACT}$ & $+\S$ & $+\Phi$ & \\
\hline \multirow[t]{2}{*}{ ACKSSuT } & 1 & 1 & & + & & \\
\hline & & & $\begin{array}{l}\text { ACKS SuT } \\
\text { ACS }_{\text {i SUT }}\end{array}$ & & & \\
\hline \multirow{4}{*}{ ACCSSuTTp } & 1 & 1 & $\mathrm{AC}$ & + & & \\
\hline & & & ACS $_{\mathrm{i}} \mathrm{SuTTp}$ & + & & \\
\hline & & & ACSuTTp & + & & \\
\hline & & & $\mathrm{TTp}$ & + & & \\
\hline Total & 132 & 127 & & & & \\
\hline
\end{tabular}

\footnotetext{
* Resistance type.

$\dagger$ Escherichia coli $\mathrm{K} 12, \mathrm{~F}^{-}, \mathrm{Lac}^{+}, \mathrm{Nal}^{\mathrm{r}}$, prototrophic; Enteric Reference Laboratory no. 14R525.

$\ddagger$ High: $10^{\circ}-1^{-2}$; Medium: $10^{-3}-10^{-5}$; Low: $10^{-6}-10^{-8}$.

$\S 57.4 \%$.

\ $42.6 \%$.

$\mathrm{A}=$ ampicillin, $\mathrm{C}=$ chloramphenicol, $\mathrm{K}=$ kanamycin, $\mathrm{S}=$ streptomycin, $\mathrm{Su}=$ sulphadiazine,

$\mathrm{T}=$ tetracycline, $\mathrm{Tp}=$ trimethoprim, $\mathrm{Nal}=$ nalidixic acid.

Subscript i shows intermediate resistance.
} 
Table II. Transfer kinetics of conjugative plasmids in $S$. dysenteriae type 1 with R-type ACSSuT isolated during the years 1974-79 and 1980-1985.

\begin{tabular}{lccc}
\hline & \multicolumn{2}{c}{ Number $(\%)$ of transfer plasmids in isolates from } \\
\cline { 2 - 4 } & & \multicolumn{2}{c}{$1980-1985$} \\
\cline { 2 - 4 } $\begin{array}{l}\text { Transfer* } \\
\text { frequency }\end{array}$ & $1974-1979$ & Plasmid & R-type ACT \\
\hline $10^{0}$ & & & $1(1 \cdot 9)$ \\
$10^{-1}$ & & $5(9 \cdot 3)$ & $13(24 \cdot 1)$ \\
$10^{-2}$ & & & $12(22 \cdot 2)$ \\
$10^{-3}$ & $2(3 \cdot 8)$ & & \\
$10^{-4}$ & $10(18 \cdot 9)$ & $4(7 \cdot 4)$ & \\
$10^{-5}$ & $24(45 \cdot 3)$ & $10(18 \cdot 5)$ & \\
$10^{-6}$ & $16(30 \cdot 2)$ & $9(16 \cdot 7)$ & \\
$10^{-7}$ & $1(1 \cdot 9)$ & & $26(48 \cdot 1)$ \\
$10^{-8}$ & $53(100 \cdot 1)$ & $28(51 \cdot 9)$ & \\
Total & & & \\
\hline
\end{tabular}

* Overnight crosses in broth mating at $37^{\circ} \mathrm{C}$ with selection on media containing chloramphenicol, ampicillin or tetracycline.

for ACSSuT resistance transferred at low frequencies from strains isolated during 1974-79. After 1980, c. $50 \%$ of the conjugative plasmids transferred at high frequencies and expressed only the ACT determinant in recipients.

Transferable or mobilisable antibiotic resistance detected in $S$. dysenteriae type 2, 3, 4, 6, and 7 is shown in table III. Conjugative plasmids coding for SSuT resistance were detected in $S$. dysenteriae types 2, 3, and 4. Non-conjugative SSu determinants in $S$. dysenteriae type 3 were mobilised by transfer factors $\mathrm{X}$ and $\Delta$. The CSSuT phenotype in types 2 and 7 and the ACST phenotype in type 3 were neither transferable nor mobilisable.

\section{Discussion}

Howe (1982) concluded that the appearance of conjugally transferable resistance among bacteria has been a recognised consequence of the use of antibiotics for some 25 years. Among antibioticresistant bacteria, $S$. dysenteriae type 1 (Shiga's bacillus) has been associated with troublesome antibiotic multiresistance mediated by $R$ plasmids. During 1969-71, Shiga's bacillus with plasmidmediated antibiotic multiresistance to CSSuT appeared in populous central America with devastating effects (Mata et al., 1969). This was closely followed by a severe but limited outbreak in Mexico City (Olarte et al., 1976). The strain contained a transmissible plasmid (R-type CSSuT) and a mobilisable plasmid encoding ampicillin resistance. $\mathbf{R}$ plasmid mediated drug resistance types CSSuT and
ACSSuT occurred in India (Macaden et al., 1980) and Bangladesh (Crosa et al., 1977).

The present study clearly demonstrated that $>$ $96 \%$ of strains of Shiga's bacillus isolated in Ethiopia harboured conjugative plasmids, most of which transferred at high frequencies. About $84 \%$ of these isolates were characteristically associated with R-type ACSSuT. It is interesting to note that there were two distinct patterns of transfer frequency associated with this R-type. The ACSSuT determinant in strains isolated before 1980 transferred at low frequencies, whereas $>50 \%$ of conjugative plasmids encountered after this time transferred at high frequencies and expressed the ACT determinant only. The introduction of a new clone of Shiga's bacillus into Ethiopia after 1980 is suspected. Genetic and molecular studies are in progress to substantiate this hypothesis.

According to Frost et al. (1981), isolates of Shiga's bacillus with R-type ACSSuT from Somalia carried conjugative group-X plasmids coding for ACT, which mobilised the SSu-determinant. On the other hand, isolates of Shiga's bacillus with the above Rtype from Central Africa had conjugative ACT plasmids that failed to mobilise the SSu-determinant (Ebright et al., 1984; Frost et al., 1985). It is possible that some of our Shiga's bacillus isolates are related to these African strains. Genetic and molecular studies are, however, needed to establish whether the determinants of drug resistance are carried on related plasmids.

Preliminary plasmid finger-print analysis of $S$. dysenteriae type- 1 isolates and their $\mathrm{R}$-plasmid 
Table III. Transferable or mobilisable antibiotic resistance in $S$. dysenteriae types 2, 3, 4, 6 and 7 isolated in Addis Ababa, Ethiopia (1974-1985)

\begin{tabular}{|c|c|c|c|c|c|}
\hline \multirow[b]{2}{*}{ Sero-type } & \multirow[b]{2}{*}{$\begin{array}{l}\text { Donor } \\
\text { R-type }\end{array}$} & \multicolumn{2}{|c|}{ Direct transfer* } & \multicolumn{2}{|c|}{ Mobilisation $\dagger$} \\
\hline & & $\begin{array}{l}\text { Number } \\
\text { tested }\end{array}$ & $\begin{array}{l}\text { Number } \\
\text { conjugative } \\
\text { (R-type) }\end{array}$ & $\begin{array}{c}\text { Number } \\
\text { tested }\end{array}$ & $\begin{array}{c}\text { Number } \\
\text { mobilised } \\
\text { (R-type) }\end{array}$ \\
\hline \multirow[t]{3}{*}{2} & $\mathrm{~S}$ & 12 & 0 & 4 & 0 \\
\hline & SSuT & 2 & $\begin{array}{l}2(\mathrm{SSuT}) \\
(\mathrm{T})\end{array}$ & & \\
\hline & CSSuT & 17 & 0 & 3 & 0 \\
\hline \multirow[t]{4}{*}{3} & $\mathrm{SSu}$ & 2 & 0 & 2 & $\begin{array}{c}2(\Delta, S S u) \ddagger \\
(X, S S u)\end{array}$ \\
\hline & SSuT & 2 & $\begin{array}{c}2(\mathrm{SSuT}) \\
(\mathrm{T})\end{array}$ & & \\
\hline & ACST & 2 & 0 & 2 & 0 \\
\hline & ACSSuT & 17 & 0 & 3 & $\begin{array}{c}3(\Delta, \mathrm{SSu}) \ddagger \\
(\mathrm{X}, \mathrm{SSu})\end{array}$ \\
\hline \multirow[t]{2}{*}{4} & SSu & 5 & 0 & 3 & 0 \\
\hline & SSuT & 1 & 1 (SSuT) & & \\
\hline 6 & SSu & 3 & 0 & 2 & 0 \\
\hline \multirow[t]{2}{*}{7} & SSu & 2 & 0 & 2 & 0 \\
\hline & CSSuT & 1 & 0 & 1 & 0 \\
\hline
\end{tabular}

* Overnight broth culture at $37^{\circ} \mathrm{C}$ and $28^{\circ} \mathrm{C}$ with E. coli $\mathrm{K} 12, \mathrm{~F}^{-}, \mathrm{Lac}^{+}, \mathrm{Nal}^{\mathrm{r}}$, prototrophic; Enteric Reference Laboratory (ERL no. 14R525).

$\dagger$ Triparental crosses with plasmids X (ERL no. 48R626) and $\Delta$ (ERL no. RT641).

$\ddagger$ Higher transfer in $\Delta$-mediated transfer $\left(10^{-3}-10^{-4}\right)$.

bearing $E$. coli counterparts has shown that the strain, which first appeared in Ethiopia in 1980, was identical with the Zairian strain (Frost et al., 1985), whereas the second strain was endemic to Ethiopia and may have an independent R-plasmid evolution.

A few of our $S$. dysenteriae type-1 isolates showed the CSSuT R-type characteristic of strains of Shiga's bacillus from Central America (Mata et al., 1970). Previous studies in Ethiopia demonstrated that antibiotic multiresistance in $S$. dysenteriae, other than type 1 , is not common (Gebre-Yohannes and Limenih, 1980; Gebre-Yohannes and Habte-Gabr, $1984 b$ ). The present study also demonstrated the relative paucity of conjugative plasmids in these serotypes. It was interesting to note that CSSuT determinants in $S$. dysenteriae types 2 and 7 , and ACST determinants in type 3 , were neither transferable nor mobilisable. However, the SSu-determinant in $S$. dysenteriae type 3 with R-type ACSSuT was efficiently mobilised by plasmids $\mathrm{X}$ and $\Delta$. It is possible that some of the above $R$-types are chromosomally mediated.

According to Frost and Rowe (1983), conjugative plasmids coding for tetracycline resistance have been detected in the genus Shigella. In this study, S. dysenteriae types 2, 3 and 4 with R-type SSuT carried conjugative plasmids coding for tetracycline resistance and, in some cases, the SSu-determinant was mobilised by the plasmid coding for tetracycline resistance.

The present study has demonstrated that R-type ACSSuT is especially prevalent in Shiga's bacillus isolates from Ethiopia. A similar situation also exists in $S$. flexneri type 2, which is the most commonly encountered serotype in Ethiopia (Gebre-Yohannes and Drasar, 1987). The WHO Scientific Working Group (1983) on antimicrobial resistance reports that there is a higher prevalence of resistance to ACSSuT in developing countries. These drugs are often freely available in the open market and are taken without medical advice. A critical reappraisal of the use of antimicrobials in developing countries is, therefore, urgently required.

Equipment and consumable items required for this study were funded by the World Health Organization. Financial assistance from the National Research Institute of Health, Ethiopia is gratefully acknowledged. We thank Drs B. Rowe and E. J. Threlfall for their help and advice in the project. 


\section{REFERENCES}

Akiba T, Koyama K, Ishiki Y, Kimura S, Fukushima T 1960 On the mechanism of the development of multiple-drugresistant clones of Shigella. Japanese Journal of Microbiology 4: 219-227.

Anderson E S, Threlfall E J 1974 The characterization of plasmids in the Enterobacteria. Journal of Hygiene 72 : 471487.

Bauer A W, Kirby W M M, Sherris J C, Turch A 1966 Antibiotic susceptibility testing by standardized single disk method. American Journal of Clinical Pathology 45: 493-496.

Crosa J H, Olarte J, Mata L J, Luttrop L K, Penaranda M E 1977 Characterization of an R-plasmid associated with ampicillin resistance in Shigella dysenteriae type 1 isolated from epidemics. Antimicrobial Agents and Chemotherapy 11 : 553-558.

Ebright J R, Moore E C, Sanborn W R, Schaberb D, Kyle J, Ishida K 1984 Epidemic Shiga bacillus dysentery in Central Africa. American Journal of Tropical Medicine and Hygiene 33: 1192-1197.

Frost J A, Rowe B, Vandepitte J, Threlfall E J 1981 Plasmid characterisation in the investigation of an epidemic caused by multiply resistant Shigella dysenteriae type 1 in Central Africa. Lancet 2: 1074-1076.

Frost J A, Rowe B 1983 Plasmid determined antibiotic resistance in Shigella flexneri isolated in England and Wales between 1974 and 1978. Journal of Hygiene $90: 27-32$.

Frost J A, Willshaw G A, Barclay E A, Rowe B, Lemmens P, Vandepitte J 1985 Plasmid characterization of drug resistant Shigella dysenteriae type 1 from an epidemic in Central Africa. Journal of Hygiene 94: 163-172.

Gebre-Yohannes A, Drasar B S 1987 Shigella dysenteriae and S. flexneri: serotype prevalence and seasonal distribution in Addis Ababa, Ethiopia (1974-85). Ethiopian Journal of Health Development 2 : 51-58.

Gebre-Yohannes A, Habte-Gabr E 1984a Shigellosis in Ethiopia I. Prevalent Shigella serogroups and serotypes. Journal of Diarrohoeal Disease Research 2: 79-82.

Gebre-Yohannes A, Habte-Gabr E $1984 b$ Shigellosis in Ethio- pia. II: Patterns of drug resistance in Shigella serotypes. Journal of Diarrhoeal Diseases Research 2: 212-216.

Gebre-Yohannes A, Limenih Y 1980 Multiple drug resistance within Shigella serogroups. Ethiopian Medical Journal 18: 7-14.

Gedebou M, Tassew A 1979 Antibiotic susceptibility patterns and $\mathbf{R}$ factor among Salmonella and Shigella isolates. Ethiopian Medical Journal 17: 99-100 (abstract).

Gedebou M, Tassew A 1982 Shigella species from Addis Ababa: frequency of isolates and in-vitro drug sensitivity. Journal of Hygiene 88: 47-55.

Howe T G B 1982 Genetic modification of the organism and antibiotic resistance. In: Stuart-Harris C H, Harris D M (eds) The control of antibiotic resistant bacteria. Academic Press, London, pp 97-117.

Macaden R, Gokul B N, Pereira P, Bhat P 1980 Bacillary dysentery due to multidrug-resistant Shigella dysenteriae type 1. Indian Journal of Medical Research 71 : 178-185.

Mata L J, Gangarosa E J, Cáceres A, Perera D R, Mejicanos M L 1970 Epidemic Shiga bacillus dysentery in Central America. I. Etiologic investigations in Guatemala, 1969. Journal of Infectious Diseases 122: 170-180.

Ochiai K, Yamanaka T, Kimura K, Sawada O 1959 Studies on the inheritance of drug resistance between Shigella strains and Escherichia coli strains. Nippon-Iji Shimpo 1861: 34-46 (in Japanese).

Olarte J, Filloy L, Galindo E 1976 Resistance of Shigella dysenteriae type 1 to ampicillin and other antimicrobial agents: strains isolated during a dysentery outbreak in a hospital in Mexico City. Journal of Infectious Diseases 133: 572-575.

Steers E, Foltz E L, Graves B S 1959 An inocula replicating apparatus for routine testing of bacterial susceptibility to antibiotics. Antibiotics and Chemotherapy (Washington) 9: 307-311.

Suzuki S, Nakazawa S, Ushida T 1956 Yearly changes of drug resistance of Shigella strains from 1951. Chemotherapy 4: 336-338 (in Japanese).

WHO Scientific Working Group 1983 Antimicrobial resistance. Bulletin of the World Health Organization 61 : 383-394. 